\title{
EVALUATION OF APPENDICECTOMY SPECIMENS FOR NEGATIVE APPENDICECTOMY AT JAWAHARLAL NEHRU INSTITUTE OF MEDICAL SCIENCES HOSPITAL, IMPHAL, INDIA
}

\author{
Yengkhom Sanatomba Singh1, Rosemary Vumkhoching², Ningombam Jitendra3 , Khumallambam Ibomcha Singh ${ }^{4}$
}

${ }^{1}$ Assistant Professor, Department of Surgery, Jawaharlal Nehru Institute of Medical Sciences (JNIMS), Imphal, Manipur.

${ }^{2}$ Associate Professor, Department of Surgery, Jawaharlal Nehru Institute of Medical Sciences (JNIMS), Imphal, Manipur.

${ }^{3}$ Professor, Department of Surgery, Jawaharlal Nehru Institute of Medical Sciences (JNIMS), Imphal, Manipur.

${ }^{4}$ Assistant Professor, Department of Surgery, Jawaharlal Nehru Institute of Medical Sciences (JNIMS), Imphal, Manipur.

\section{BACKGROUND}

ABSTRACT

Acute appendicitis is the most common intra-abdominal condition requiring emergency surgery. Past reports have shown that up to $30 \%$ of appendices have been removed after clinical diagnosis of acute appendicitis, which may be normal on histopathological examination. In spite of advanced technology and vast knowledge about the condition, it remains a difficult task for clinicia ns to diagnose it cent percent accurately. Emergency appendicectomy is performed to prevent morbidity and mortality due to perforation and gangrenous changes. In such situations, a certain percentage of normal appendices are found to be removed due to misdiagnosis. There is general agreement that highly competent surgeons make false positive diagnosis of acute appendicitis and remove normal appendices about $20 \%$ to $25 \%$. The discomfort and risks associated with an exploratory laparotomy and discovering "no disease" are far outweighed by the morbidity and mortality (about 2\%) associated with perforation (Singhal R et al, 2007). ${ }^{1}$

\section{MATERIALS AND METHODS}

This study was a prospective study conducted in Jawaharlal Nehru Institute of Medical Sciences, Imphal, Manipur, India from April 2010 to March 2017. 1000 cases of appendicectomy specimens were examined histopathologically to confirm for acute appendicitis. Detailed history was taken, physical examination and relevant laboratory investigations were performed during the clinical encounter. The diagnosis of acute appendicitis was made clinically and was confirmed after histopathological examination of the removed appendix.

\section{RESULTS}

Out of 1000 appendix specimens sent for histopathological examination, 440 (44\%) showed simple appendicitis, 240 (24\%) showed gangrenous appendicitis, 200 (20\%) showed perforated appendicitis and 120 (12\%) showed no appendicitis.

\section{CONCLUSION}

The diagnosis of acute appendicitis is based on clinical evaluation. Laboratory tests and imaging techniques add very little to the diagnosis. A definite diagnosis can be obtained only at surgery and after histopathological examination of the removed appendix. In children and elderly persons, the diagnosis should be made at the earliest and appendicectomy should be performed without delay to reduce the rate of perforation and gangrenous changes of the appendix.

\section{KEYWORDS}

Appendicitis, Negative Appendicectomy, Histopathological Examination, Perforation, Gangrenous Appendix.

HOW TO CITE THIS ARTICLE: Singh YS, Vumkhoching R, Jitendra N, et al. Evaluation of appendicectomy specimens for negative appendicectomy at Jawaharlal Nehru Institute of Medical Sciences Hospital, Imphal, India. J. Evolution Med. Dent. Sci. 2018;7(18): 2214-2217, DOI: $10.14260 /$ jemds/2018/498

\section{BACKGROUND}

The appendix is a worm-like extension of the caecum and has been called the Vermiform appendix. Its average length is 8 to $10 \mathrm{~cm}$ (ranging from 2 to $20 \mathrm{~cm}$ ). This organ appears during the $5^{\text {th }}$ month of gestation and several lymphoid follicles are scattered in its mucosa.

Appendicitis is the inflammation of the inner lining of the appendix that spreads to the other parts. It may occur for

'Financial or Other Competing Interest': None.

Submission 21-03-2018, Peer Review 13-04-2018,

Acceptance 20-04-2018, Published 30-04-2018.

Corresponding Author:

Dr. Rosemary Vumkhoching,

Associate Professor

Department of Surgery,

Jawaharlal Nehru Institute of Medical Sciences (JNIMS),

Imphal-795005, Manipur.

E-mail: rosemanna69@gmail.com

DOI: $10.14260 /$ jemds $/ 2018 / 498$

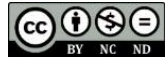

several reasons such as infection of the appendix, but the most important step is the obstruction of the appendiceal lumen.

Disease of the appendix loom large in surgical practice; appendicitis is the most common acute abdominal condition the surgeon is called on to operate. Appendicitis is one of the best known medical entities and yet may be one of the most difficult diagnostic problems to confront the emergency physician. There is general agreement that highly competent surgeons make false diagnosis of acute appendicitis and remove normal appendices about $20 \%$ to $25 \%$ of the times. The discomforts and risks associated with an exploratory laparotomy and discovering "no disease" are far outweighed by the morbidity and mortality (about $2 \%$ ) associated with perforation, Baraev TM 2000. ${ }^{2}$

Despite long experience with the diagnosis of acute appendicitis and a crowded literature on the subject, rates of negative findings on appendicectomy have not decreased even today. Except for a few reports of negative findings on appendicectomy below $10 \%$, most recent study reports rates between $15 \%$ and $34 \%$. The situation is the same regarding 
the rate of complicated appendicitis, which has not changed substantially over time, remaining between $15 \%$ and $30 \%$. Sonogram or CT scan may shorten delay in diagnosis in equivocal cases. These imaging modalities can, however, delay appropriate surgery, either while the patient is waiting the result or because of false negative result. The importance of clinical judgement has been underlined by others. Observation and repeated examinations may lead to favourable clinical outcomes in the ever-changing diagnosis of appendicitis, Bendeck SE, et al, 2002.3

Although, the clinical presentation of acute appendicitis is typical in more than $70 \%$ of the cases, about $30 \%$ of the patients have an uncertain pre-operative diagnosis. Consequently, the rate of unnecessary laparotomy for appendicitis is as high as $20-25 \%$. The rate is even higher in (34 - 45\%) in women of childbearing age because of the prevalence of disease of the female pelvic organs and complications of pregnancy in this group, Chang FC et al $1973^{4}$ and Dunn EL et al 1982.5

Although, the history and physical examination remain paramount, imaging studies have an increasingly important role in cases of equivocal presentation in diagnosis of acute appendicitis. Notwithstanding advances in modern radiographic imaging and diagnostic laboratory investigations, the diagnosis of acute appendicitis remains essentially clinical requiring a mixture of observation, clinical acumen and surgical science, Brown SP $2000 .^{6}$

\section{Objective}

This study is carried out to judge the accuracy of diagnosis of acute appendicitis, diagnosed from history taking and clinical examinations.

\section{MATERIALS AND METHODS}

This is a prospective observational study conducted at Jawaharlal Nehru Institute of Medical Sciences, Imphal, Manipur, India, from April 2010 to March 2017. One thousand cases of acute appendicitis that attended the outpatients' department and emergency services of Jawaharlal Nehru Institute of Medical Sciences were admitted and studied. A detailed history of all the patients were taken with reference to the duration of onset, nature and site of pain, presence of nausea, vomiting, fever and history of same illness in the past. A detailed physical examination of each patient was undertaken. Relevant laboratory investigations were taken during the initial clinical encounter.

The diagnosis of acute appendicitis was made clinically and was confirmed after histopathological examination of the removed appendix.

After resuscitation and preparation, all the patients were taken up for surgery. The removed appendix was sent for histopathological examination. The patients were considered to have a negative appendicectomy when the histopathological reports indicated no evidence of inflammation of the appendix. All the findings of each and every case were recorded in a standard proforma, which was specially designed for this study.

\section{Exclusion Criteria}

Patients who were previously admitted for recurrent appendicitis and readmitted for interval appendicectomy and those who are already diagnosed by ultrasonography or CT scan were not included in the study.

\section{RESULTS}

Age and Sex Distribution.

\begin{tabular}{|c|c|c|c|}
\hline \multirow{2}{*}{$\begin{array}{c}\text { Age (In } \\
\text { Years) }\end{array}$} & Male & Female & \multirow{2}{*}{ Total (\%) } \\
\cline { 2 - 3 } 16 or less & 80 & 40 & $120(12 \%)$ \\
\hline $16-30$ & 340 & 120 & $460(46 \%)$ \\
\hline $30-50$ & 140 & 180 & $320(32 \%)$ \\
\hline$>50$ & 100 & 0 & $100(10 \%)$ \\
\hline Total & $\mathbf{6 6 0}$ & $\mathbf{3 4 0}$ & $\mathbf{1 0 0 0}$ \\
\hline \multicolumn{4}{|c}{ Table 1. Showing Age and Sex Distribution } \\
\hline
\end{tabular}

Highest incidence of acute appendicitis was found in the age group of 16 - 30 years (46\%) and lowest incidence in the age group above 50 years (10\%). Acute appendicitis was found more common in males (66\%) than in females (34\%), malefemale ratio being 1.94: 1 .

\begin{tabular}{|c|c|c|c|}
\hline \multicolumn{2}{|c|}{ Symptoms } & $\begin{array}{c}\text { Number of } \\
\text { Patients }\end{array}$ & $\begin{array}{c}\text { Percentage } \\
\text { (\%) }\end{array}$ \\
\hline \multirow{3}{*}{ Pain abdomen } & Typical & 940 & $94 \%$ \\
\cline { 2 - 4 } & Atypical & 60 & $6 \%$ \\
\hline Anorexia & 920 & $92 \%$ \\
\hline \multicolumn{2}{|c|}{ Nausea } & 920 & $92 \%$ \\
\hline \multicolumn{2}{|c|}{ Vomiting } & 280 & $28 \%$ \\
\hline Fever & 160 & $16 \%$ \\
\hline \multirow{2}{*}{ Bowel habits } & Diarrhoea & 20 & $2 \%$ \\
\cline { 2 - 4 } & Burning micturition & 180 & $18 \%$ \\
\hline \multicolumn{2}{|c|}{ Table 2. Showing the Presenting Symptoms } \\
\hline
\end{tabular}

In this study, pain abdomen has been divided as typical, arising around the umbilicus or epigastrium and later shifted to the right iliac fossa and atypical, starting and remaining in the right iliac fossa. Most of the patients presented with pain in the right lower quadrant. There was history of shifting of pain to the right iliac fossa in 940 patients (94\%). Whereas in 60 patients $(6 \%)$, the pain started and remained in the right lower quadrant. In 920 cases (92\%), there was history of Anorexia and 280 patients (28\%) gave history of vomiting. Fever was present in 160 patients (16\%). 20 patients (2\%) had diarrhoea and $180(18 \%)$ gave history of constipation before the onset of pain. 20 patients (2\%) gave history of burning micturition.

\begin{tabular}{|c|c|c|}
\hline Tenderness & No. of Patients & Percentage (\%) \\
\hline Periumbilical & 700 & $70 \%$ \\
\hline Right Iliac Fossa & 1000 & $100 \%$ \\
\hline McBurney's Point & 1000 & $100 \%$ \\
\hline Rebound Tenderness & 760 & $76 \%$ \\
\hline Generalized Tenderness & 260 & $26 \%$ \\
\hline
\end{tabular}

Table 3. Showing Tenderness on Abdominal Examination

On palpation of the abdomen 700 patients (70\%) showed periumbilical tenderness, 1000 patients (100\%) showed right iliac fossa tenderness, 1000 patients (100\%) showed tenderness over McBurney's point, 760 patients (76\%) showed rebound tenderness and 260 patients $(26 \%)$ showed generalised tenderness. 


\begin{tabular}{|c|c|c|c|}
\hline \multicolumn{2}{|c|}{ Sign } & $\begin{array}{c}\text { No. of } \\
\text { Patients }\end{array}$ & $\begin{array}{c}\text { Percentage } \\
\text { (\%) }\end{array}$ \\
\hline \multirow{3}{*}{ Guarding } & $\begin{array}{c}\text { Right iliac } \\
\text { fossa }\end{array}$ & 740 & $74 \%$ \\
\cline { 2 - 4 } & Generalised & 80 & $8 \%$ \\
\hline \multicolumn{2}{|c|}{ Rovsing's Sign } & 820 & $82 \%$ \\
\hline \multicolumn{2}{|c|}{ Cope's Psoas Test } & 780 & $78 \%$ \\
\hline \multicolumn{2}{|c|}{ Cope's Obturator Sign } & 160 & $16 \%$ \\
\hline \multicolumn{2}{|c|}{ Table 4. Showing Presenting Signs } \\
\hline
\end{tabular}

On trying to elicit the classical signs of acute appendicitis, 740 patients $(74 \%)$ were found to have muscle guarding on right iliac fossa, 80 patients (8\%) had generalised guarding, 820 patients (82\%) had positive Rovsing's sign, 780 patients (78\%) had positive Cope's Psoas sign, 160 patients (16\%) had Cope's Obturator sign positive.

\begin{tabular}{|c|c|c|c|}
\hline \multicolumn{2}{|c|}{ Operative Findings } & No. of Patients & Percentage (\%) \\
\hline \multirow{4}{*}{$\begin{array}{l}\text { Position } \\
\text { of } \\
\text { appendix }\end{array}$} & Retrocaecal & 760 & $76 \%$ \\
\hline & Pelvic & 180 & $18 \%$ \\
\hline & Subhepatic & 40 & $4 \%$ \\
\hline & Subcaecal & 20 & $2 \%$ \\
\hline \multicolumn{2}{|c|}{ Gangrene } & 240 & $24 \%$ \\
\hline \multicolumn{2}{|c|}{ Perforation } & 200 & $20 \%$ \\
\hline \multicolumn{2}{|c|}{ Faecolith } & 420 & $42 \%$ \\
\hline \multicolumn{2}{|c|}{ Inflamed appendix } & 880 & $88 \%$ \\
\hline \multicolumn{2}{|c|}{ Non-inflamed appendix } & 120 & $12 \%$ \\
\hline \multicolumn{4}{|c|}{ Table 5. Showing Operative Findings } \\
\hline
\end{tabular}

Operative findings regarding the positions of appendix were retrocaecal 760 (76\%), pelvic $180(18 \%)$, subhepatic 40 (4\%) and subcaecal 20 (2\%). 240 (24\%) had gangrene on the appendix, 200 patients $(20 \%)$ had perforation, 420 patients (42\%) had faecolith in the appendiceal lumen, 880 (88\%) appendices were found inflamed and 120 appendices (12\%) were found non-inflamed on histopathological examination.

\begin{tabular}{|c|c|c|}
\hline $\begin{array}{l}\text { Histopathological } \\
\text { Findings }\end{array}$ & $\begin{array}{c}\text { Number of } \\
\text { Patients }\end{array}$ & $\begin{array}{c}\text { Percentage } \\
\text { (\%) }\end{array}$ \\
\hline Simple appendicitis & 440 & $44 \%$ \\
\hline Gangrenous appendicitis & 240 & $24 \%$ \\
\hline Perforated appendicitis & 200 & $20 \%$ \\
\hline No appendicitis & 120 & $12 \%$ \\
\hline Total & 1000 & $100 \%$ \\
\hline
\end{tabular}

Out of 1000 appendix specimens sent for histopathological examination, $440(44 \%)$ specimens showed simple appendicitis, 240 (24\%) specimens showed gangrenous appendicitis, $200(20 \%)$ specimens showed perforated appendicitis and $120(12 \%)$ specimens showed no appendicitis.

\section{DISCUSSION}

The present prospective observational study consists of 1000 patients aged 12 years to 70 years, with mean age of 31.64 years which is similar with the findings of Gaensler et al (1989), ${ }^{7}$ in which the mean age of patients with appendicitis was reported to be 26 years. In the study the male-to-female ratio of patients suffering from appendicitis was 1.9: 1, which is in consistence with the findings of Madan S (2000) ${ }^{8}$ who found it to be $1.7: 1$.
In the present series, the majority of patients were from middle class income group (70\%). Similar finding was reported by Mann CV (1995). ${ }^{9}$

In this study 720 patients (72\%) had pain starting around the umbilicus, 220 patients (22\%) in the epigastrium and 60 patients (6\%) in the right lower quadrant. 940 patients (94\%) had shifting pain to the right lower quadrant. All the 1000 patients had pain at the right lower quadrant at the time of examination. Tenderness was found at the right iliac fossa and McBurney's point in all the patients. Rebound tenderness was found in $760(76 \%)$ patients and muscle guarding was found in $740(74 \%)$ patients in the right iliac fossa and in $80(8 \%)$ patients all over the abdomen.

Mann CV (1991) ${ }^{10}$ stated that it is rare to find a child with appendicitis who has not vomited, and they usually have complete aversion to food, in addition they do not sleep during the attack. In this series, 920 (92\%) had history of nausea and 280 patients $(28 \%)$ had history of vomiting.

Rappaport WD et al (1989) ${ }^{11}$ reported that right lower quadrant pain or tenderness was present in $95 \%$ of all simple appendicitis and $71 \%$ with advanced appendicitis, and he further stated that even in very young child history and physical examinations were the keys for early diagnosis. Our present findings are in consistence with this.

As part of the protocol, these patients did not undergo ultrasonography and CT scan. A recent study comparing clinical versus ultrasonography evaluation of acute appendicitis found that patients undergoing ultrasonography before appendicectomy have a delay before operation, a higher rate of misdiagnosis and more postoperative complications (Emil S et al 2001). ${ }^{12}$ In addition, Brenner D et al (2001) stated that evidence suggests that the radiation from CT scans causes a slightly increased lifetime risk of malignancy.

In the present series, the duration of hospital stay ranges from 4 to 11 days. With mean hospital stay of 7.56 days, patients with postoperative complications had longer hospital stay. Curran TJ and Muenchow SK (1993) found the average hospital stay to be 8.7 days. An $8.1 \%$ rate of negative appendicectomy represents a good clinical performance, because a rate of $15 \%$ is still considered acceptable. Despite many trials to improve these results, it has become apparent that in most units, the rate of normal appendix removal remains around 155 (Bergeron E, 2006) ${ }^{13}$ and 16.7\% (Wen SW et al 2011). ${ }^{14}$

Singhal R et al (2007), 1 in their histopathological examination of 348 removed appendices for appendicitis found that 38 appendices were normal, giving the negative appendicectomy rate of $10.9 \%$. In our present series, 120 out of 1000 appendices removed for appendicitis were found noninflamed. This gives a negative appendicectomy rate of $12 \%$. The negative appendicectomy rate was higher in females and they were in the reproductive age group (28 - 42 years).

\section{CONCLUSION}

The diagnosis of acute appendicitis is primarily clinical, and the accuracy rate is related to the experience of the evaluating surgeon. The most reliable guidelines in deciding whether an operation is indicated are a history of anorexia and pain in the right lower quadrant in combination with presence of persistent, focal and reproducible tenderness at McBurney's point, Bergeron E 2002. 
Early diagnosis of acute appendicitis reduces the morbidity of the disease. The clinical picture of early appendicitis is not atypical. Right lower quadrant signs and symptoms are usually present. Progression of pain, nausea and anorexia are symptoms that could usefully help to distinguish acute appendicitis from other causes of acute pain abdomen.

A detailed history, clinical examination and their interpretation are the most important factors to come to a diagnosis of acute appendicitis. Menstrual history should always be taken while evaluating women of reproductive age, and their abdominal examination should be carried out in profound detail to reduce the rate of negative appendicectomy.

In children and elderly persons, the diagnosis should be made at the earliest and appendicectomy should be performed without losing time to reduce the rate of perforation and gangrenous changes of the appendix.

\section{REFERENCES}

[1] Singhal R, Angmo N, Somaiah N, et al. A retrospective review of the histopathology and clinicopathologic correlates of appendicitis removed from patients of acute appendicitis. Minerva Chir 2007;62(1):11-8.

[2] Baraev TM. Morphology and pathology of the appendix and their clinical significance. Arkh Pathol 2000;62(4):57-9.

[3] Bendeck SE, Nino-Murcia M, Berry GJ, et al. Imaging for suspected appendicitis: negative appendicectomy and perforation rates. Radiology 2002;225(1):131-6.

[4] Chang FC, Hogle HH, Welling DR. The fate of negative appendix. Am J Surg 1973;126(6):752-4.
[5] Dunn EL, Moore EE, Elerdings SC, et al. The unnecessary laparotomy for appendicitis: can it be decreased? Am J Surg 1982;48(7):320-3.

[6] Brown SP. Diagnosis. Hamilton Bailey's emergency surgery. 13th edn. London: Arnold 2000: p. 301-6.

[7] Gaensler EHL, Jeffry RB, Laing FC, et al. Sonography in patients with suspected acute appendicitis: value in establishing alternative diagnosis. AJR 1989;152(1):49-51.

[8] Samuel M. Pediatric appendicitis score. J Pediatr Surg 2002;37(6):877-81.

[9] Mann CV. The vermiform appendix. Bailey and Love's short practice of surgery. $22^{\text {nd }}$ edn. London: Chapman and Hall 1995: p. 828-41.

[10] Mann CV. The vermiform appendix. Bailey and Love's short practice of surgery. 22nd edn. London: Chapman and Hall 1991: p. 828-41.

[11] Rappaport WD, Petterson M, Stanton C. Factors responsible for the high perforation rate seen in early childhood appendicitis. Am J Surg 1989;55(10):602-5.

[12] Emil S, Mikhail P, Laberge JM, et al. Clinical versus sonographic evaluation of acute appendicitis in children: a comparison of patient characteristics and outcomes. J Pediatr Surg 2001;36(5):780-3.

[13] Bergeron E. Clinical judgment remains of great value in the diagnosis of acute appendicitis. J Can Chir 2006;49(2):96-100.

[14] Wen SW, Demissie K, August D, et al. Level of aggregation for optimal epidemiological analysis: the case of time to surgery and unnecessary removal of the normal appendix. J Epidem Comm Health 2001;55(3):198-203. 